\title{
RESPOSTA DO FUNGO MICORRÍZICO ARBUSCULAR RHIZOPHAGUS CLARUS E ADIÇÃO DE SUBSTÂNCIAS HÚMICAS NO CRESCIMENTO DO TOMATEIRO (SOLANUM LYCOPERSICUM L.)
}

\author{
Response of arbuscular mycorrbizal fungal Rhizophagus clarus and the addition of humic substances in growth of tomato \\ (Solanum lycopersicum L.)
}

Mylena Barbosa da Silva ${ }^{1}$, Fernanda Custódio Oliver ${ }^{1}$, Rayane Monique Sete da Cruz ${ }^{2}$, Bianca de Almeida Marchi ${ }^{1}$, Luiz Renato Marques Das Almas ${ }^{3}$, Odair Alberton ${ }^{4 *}$

\begin{abstract}
${ }^{1}$ Discentes do curso em Engenharia Agronômica da Universidade Paranaense - UNIPAR, Umuarama - PR. 2Discente do Programa de Pós-graduação em Biotecnologia Aplicada à Agricultura da UNIPAR. Umuarama - PR. ${ }^{3}$ Discente do curso em Química Industrial da Universidade Paranaense - UNIPAR, Umuarama - PR. 4Docente titular da Universidade Paranaense - UNIPAR, Umuarama - PR. E-mail: odair@prof.unipar.br ou
\end{abstract} oalberton@yahoo.com.br (*AUTOR PARA CORRESPONDÊNCIA).

Artigo enviado em 30/05/2017, aceito em 14/08/2017 e publicado em 29/09/2017.

Resumo - A utilização de fungos micorrízicos arbusculares (FMAs) pode otimizar a produção, uma vez que a simbiose entre o fungo e a planta pode promover o aumento da absorção de nutrientes. O objetivo deste estudo foi avaliar o efeito da inoculação de fungo micorrízico arbuscular e a adição de substâncias húmicas (SHs) na cultura do tomateiro. Para isso, foram avaliados: a densidade dos esporos, a colonização radicular por FMA, a produção de fitomassa, o índice de clorofila e o conteúdo de fósforo na parte aérea. O delineamento experimental foi inteiramente casualizado com quatro tratamentos e cinco repetições em vasos com $3 \mathrm{~L}$ de substrato (areia + vermiculita 1:1 v/v, estéril) em casa de vegetação da Universidade Paranaense - UNIPAR, Umuarama, PR. Os tratamentos foram os seguintes: 1 - sem inoculação de FMA e sem adição de SHs, 2 - com inoculação de FMA e sem adição de SHs, 3 sem inoculação de FMA e adição de SHs, 4 - com inoculação de FMA e adição de SHs. A densidade de esporos, a colonização radicular por FMA, a massa seca da parte aérea e total e o conteúdo de fósforo das folhas foram aumentados significantemente com a inoculação de FMAs e adição de SHs. O índice de clorofila aumentou significantemente a adição de SHs. Conclui-se que com a inoculação de FMAs e adição de SHs promove o crescimento e o aumento do conteúdo de fósforo na planta de tomateiro.

Palavras-chave: ácido fúlvico, ácido húmico, Rhirophagus clarus.

Abstract - The utilization of arbuscular mycorrhizal fungi (AMF) can improve plant production, due the symbiosis between the fungus and plants can promote the increasing of nutrient uptake. This study aimed to evaluate the effect of AMF inoculation and the addition of humic substances (HSs) in tomato cultivation. For this, it has been analyzed the density of spores and the root colonization by the AMF, phytomass' production, the chlorophyll index and the content of phosphorus of aerial part. The experiment has been fully made with four treatments and five repetitions in three-litter-pot of substrate (sand + vermiculite 1:1 v/v, sterile) in the greenhouse at Universidade Paranaense UNIPAR in Umuarama, Paraná State. The treatments have been the following: 1 - with no inoculation of AMF and with no addiction of HSs, 2 - with inoculation of AMF and with no addiction of HSs, 3 - with no inoculation of AMF and addiction of HSs, 4 - with inoculation of AMF and addiction of HSs. The density of spores and the radicular colonization by AMF, the dry mass of aerial part and total, the content of phosphorus in aerial part, have increased significantly with the inoculation of AMF and addiction of HSs. The chlorophyll index has increased significantly the addiction of SHs. Concluded that the inoculation of AMF and addiction of HSs it promotes the growth and the increase of phosphorus content in the tomato plant.

Keywords: fulvic acid, humic acid, Rhizophagus clarus. 


\section{INTRODUÇÃO}

Atualmente um dos grandes desafios da sociedade é garantir à produção de alimentos em larga escala de forma sustentável, garantindo à qualidade de vida no presente a para futuras gerações. Paralelamente precisamos aumentar a produtividade e a manutenção da qualidade do alimento produzido, sempre zelando pelos recursos naturais, ao encontro da sustentabilidade.

O tomate (Solanum lycopersicum L.) é um fruto da família Solanaceae, pertencente ao grupo das angiospermas eudicotiledôneas, considerada planta de grande importância econômica. O Brasil é o oitavo maior produtor mundial, com uma área de $55 \mathrm{mil} \mathrm{ha}$, totalizando 3,5 milhões de toneladas no ano de 2016, o que significa uma média de $65 \mathrm{t}$ ha-1, ou seja, o dobro da média da produtividade mundial, que chega a $27 \mathrm{t}$ ha-1 (BRASIL, 2016). A produção é destinada ao consumo in natura e à indústria e seu cultivo exige muita mão de obra e amplo uso de agrotóxico, pois apresenta alta infestação de pragas e doenças e, portanto com alto custo na produção. Por conseguinte, o uso de agrotóxico pode ocasionar alguns riscos, com manejo inadequado dos produtos, como trazer prejuízo à saúde dos consumidores e, principalmente de produtores, contaminação dos solos além de elevar o custo da produção (HART et al., 2015; BONA et al., 2017).

Buscando uma produção sustentável, estudos que mostraram os fungos micorrízicos arbusculares (FMAs) têm aumentado à produção de várias plantas, inclusive a cultura do tomate (BAUM et al., 2015; HART et al., 2015; DOUDS Jr. et al., 2016). Com isso, pode ser uma alternativa, para aumentar a produção, sem a aplicação de insumos agrícolas. Os FMAs formam associações simbióticas mutualistas com as raízes das plantas. A relação simbiótica entre FMA e plantas inicia quando há uma troca de sinais entre o hospedeiro e o fungo, mediante penetração do micélio inter ou intracelular nas raízes, onde o fungo absorve nutrientes do solo e os transfere para a planta. Por outro lado, a planta disponibiliza carboidratos sintetizados pela fotossíntese para os FMAs (SMITH \& READ, 2008; BAUM et al., 2015; HART et al., 2015; PEINADO-GUEVARA et al., 2017). A utilização desses pode aperfeiçoar a produção, em virtude de um provável aumento da absorção de água e nutrientes como e fósforo $(\mathrm{P})$, além, de contribuir com o aumento a resistência a fitopatógenos e estresses abióticos (hídrico, salino e etc) (BAUM et al., 2015; CANDIDO et al. 2015; HART et al., 2015; CHITARRA et al., 2016; SHARMA; SHARMA, 2017).
As substâncias húmicas ( $\mathrm{SHs}$ ), são o resultado do produto final da decomposição de resíduos orgânicos, que apresenta solo, sedimentos, e matéria orgânica a matéria orgânica do solo que é formada por material lábil (ácidos orgânicos facilmente degradáveis) e recalcitrante (lignina, quitina e etc). Ambos materiais lábil e recalcitrante, podem ficar protegido pelos agregados do solo, o que significa que é melhor dividir a matéria orgânica em material protegido e não protegido da decomposição. A indústria separa o material da decomposição da matéria orgânica e de vermicompostagem, como ácido fúlvico, ácido húmico e humina (PINHEIRO et al., 2010; DEMIR et al., 2015). Essas substâncias são compostas por ácidos orgânicos, solúveis em água, encontradas em lodo de esgoto, compostos orgânicos, leonardita, turfa e produtos comerciais (LIMA et al., 2011). Ácidos húmicos com fração relativa mais estável das SHs, a uma coloração escura, alto teor de anéis aromáticos, grupos funcionais hidrofílicos com oxigênio, obtém diversas estruturas e composições elementares, nas quais se mostram dependentes de suas fontes de origem e método de extração (DEMIR et al., 2015; RADY \& REHMMAN, 2016).

Demir et al. (2015), as SHs podem aumentar o crescimento e a produtividade das plantas, pois influenciam de forma positiva no transporte de íons, melhorando a absorção de nutrientes, aumentando a taxa de respiração e velocidade das reações enzimáticas do ciclo de Krebs resultando em maior produção de ATP, aumentando o teor de clorofila e a velocidade e síntese de ácidos nucléicos. Além disso, possui efeito seletivo sobre a síntese proteica e maior ou inibição da atividade de enzimas. No estudo de Adini et al. (1998) com aplicação de ácidos húmicos no tomateiro, observou-se um aumento no crescimento radicular e absorção de nutrientes, como o nitrogênio e o P, sendo o mesmo observado por Rady \& Rehmman, (2016). Os autores sugerem que há necessidade de mais estudos para elucidar o papel das $\mathrm{SH}$, como ácido húmico e a interação com micro-organismos do solo.

No presente estudo, espera-se encontrar aumento na produção do tomateiro com a inoculação com FMA e ou com a adição de SHs, levando a uma produção sustentável desta cultura. Desse modo, o objetivo do estudo foi avaliar o efeito da inoculação do FMA Rhirophagus clarus e adição de SHs na cultura do tomateiro.

\section{MATERIAL E MÉTODOS}

O experimento foi conduzido em casa de vegetação sob delineamento experimental inteiramente casualizado, em esquema fatorial, com quatro 
tratamentos e cinco repetições. Os tratamentos foram: 1 - sem inoculação de fungo micorrizico arbuscular (FMA) e sem adição de substâncias húmicas (SHs), 2 com inoculação de FMA e sem adição de SHs, 3 - sem inoculação de FMA e adição de $\mathrm{SHs}$, 4- com inoculação de FMA e adição de SHs.

As mudas de tomateiro tipo cereja com 12 a $15 \mathrm{~cm}$ de altura foram obtidas no comércio especializado em venda de mudas de hortaliças. As mudas estavam sendo crescidas em bandejas para mudas com substrato orgânico vegetal. No momento da aquisição estas estavam com cerca de $16 \mathrm{~cm}$ de altura, e 30 dias de semeadura. As plântulas foram transplantadas para vasos de plástico (3 L) contendo substrato areia:vermiculita, na proporção de 1:1, (v:v), esterilizado em autoclave, na temperatura de $121{ }^{\circ} \mathrm{C}$, durante 30 minutos, sendo novamente auto clavado após 24 horas.

Para os tratamentos com FMA foram inoculados no terço superior dos vasos, $110 \mathrm{~g}$ do solo inóculo que continha 100 esporos do fungo Rhizophagus clarus, proveniente do banco de Glomales da UNIPAR, multiplicado em plantas de milho (Zea mays L.) (LERMEN; MOHR; ALBERTON, 2015). Os tratamentos com substâncias húmicas foram compostos por $75 \%$ de ácido húmico e $25 \%$ de ácido

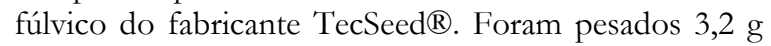
de SHs para $1 \mathrm{~L}$ de água deionizada (dose de $2 \mathrm{~L} \mathrm{ha}^{-1}$, conforme fabricante) e distribuídas em 10 vasos com SHs. Todos os vasos foram irrigados a cada dois dias com solução nutritiva completa (HOAGLAND; ARNON, 1950). Nos tratamentos não inoculados (controles) foram adicionados $100 \mathrm{~mL}$ do filtrado do solo inoculo (100 g do solo inóculo $\mathrm{L}^{-1}$ de água deionizada estéril). Desse modo obteve-se apenas o efeito dos FMAs inoculados.

Após 48 dias, as plantas de tomate foram coletadas para a determinação das variáveis, densidade de esporos do FMA, colonização radicular por FMA, matéria seca das raízes, folhas, massa seca total, relação entre massa seca da parte aérea/raiz, índice de clorofila e teor de fósforo da parte aérea.

\section{Avaliação da colonização radicular e densidade de esporos por FMAs}

As raízes foram coradas com azul de tripano (0,05\%) conforme Phillips e Hayman (1970). A percentagem de segmentos radiculares colonizados foi determinada sob microscópio óptico (100X) (GIOVANNETTI; MOSSE, 1980).

Os esporos foram extraídos do solo de acordo com técnica descrita por Gerdemann e Nicolson (1963), a partir de $10 \mathrm{~g}$ de solo e submetido ao peneiramento úmido nas malhas de $0,710 \mathrm{~mm}$ e de 0,053 mm de abertura. Após os esporos transferidos para placas de Petri para a contagem sob microscópio estereoscópio (40X).

\section{Massa seca da parte aérea e massa seca da raiz}

As plantas foram acondicionadas em estufa por $48 \mathrm{~h}$, com temperatura de $65^{\circ} \mathrm{C}$, pesada em balança digital para obter a massa seca da parte aérea e a massa seca da raiz.

\section{Índice de Clorofila}

No início do florescimento da planta, foi realizada a análise do índice de clorofila, medindo-se em 3 folhas completamente desenvolvida vasos ${ }^{-1}$, sempre as do meio da planta, para a medição foi utilizado um clorofilômetro marca clorofiLOG ${ }^{\circledR}$ modelo CFL 1030, conforme o fabricante (FALKER, 2008).

\section{Determinação de fósforo das folhas}

Para a determinação do fósforo no tecido vegetal, a digestão foi feita por via seca, em mufla a 500 ${ }^{\circ} \mathrm{C}$, depois foram feitas as leituras em espectrofotômetro, usando filtro vermelho e comprimento de onda de $660 \mathrm{~nm}$, conforme Silva (2009).

\section{Análise estatística}

Os resultados foram testados quanto à equidade das variâncias com o teste de Levene, e quanto à normalidade os dados discrepantes foram identificados por gráficos em caixa (box-plot), utilizando o programa estatístico SPSS 22.0 para o Windows (SPSS Inc., Chicago, IL, USA). A análise de variância (ANOVA) foi feita analisando a interação entre as doses de SHs e inoculação de FMA. Foi empregado o teste de Duncan a $5 \%$ de probabilidade para testar as diferenças estatísticas entre as médias.

\section{RESULTADOS E DISCUSSÃO}

$\mathrm{Na}$ tabela 1 estão apresentados os dados referentes à densidade de esporos e a colonização radicular por FMA. Observou-se diferença significativa entre os tratamentos com FMA e a interação com o FMA e as substâncias húmicas (SHs). A densidade de esporos e a colonização radicular por FMA aumentou quando se aplicou as SHs (Tabela 1). 
Tabela 1 - Valores de $p$ da análise de variância (ANOVA) referente a densidade de esporos do fungo micorrízico arbuscular (FMA) ( $\mathrm{n}^{\circ} \mathrm{g}^{-1}$ de solo seco) e colonização radicular (\%) por FMA do tomateiro inoculado com o FMA Rhizophagus clarus sob a adição ou não de substâncias húmicas (SHs).

\begin{tabular}{lll}
\hline Tratamentos & Densidade de Esporos & Colonização \\
\hline FMA & $0,27 \pm 0,02 \mathrm{~b}$ & $0,78 \pm 0,09 \mathrm{~b}$ \\
Sem FMA & $2,11 \pm 0,17 \mathrm{a}$ & $14,59 \pm 1,42 \mathrm{a}$ \\
Com FMA & $<0,001$ & $<0,001$ \\
Valor de $P$ & & \\
SHs & $0,98 \pm 0,25$ & $5,83 \pm 1,73$ \\
Sem SHs & $1,39 \pm 0,37$ & $9,53 \pm 2,97$ \\
Com SHs & 0,297 & 0,382 \\
Valor de $P$ & & \\
FMA x SHs & $0,26 \pm 0,03 \mathrm{c}$ & $0,77 \pm 0,11 \mathrm{c}$ \\
Sem FMA e SHs & $1,72 \pm 0,14 \mathrm{~b}$ & $10,90 \pm 0,87 \mathrm{~b}$ \\
Com FMA e sem SHs & $0,30 \pm 0,03 \mathrm{c}$ & $0,80 \pm 0,15 \mathrm{c}$ \\
Sem FMA e com SHs & $2,49 \pm 0,18 \mathrm{a}$ & $18,27 \pm 1,26 \mathrm{a}$ \\
Com FMA e com SHs & $<0,001$ & $<0,001$ \\
Valor de $P$ & Média \pm erro padrão. Médias seguidas da mesma letra na coluna, não diferem estatisticamente entre si pelo teste de Duncan (p $\leq 0,05)$.
\end{tabular}

Tabela 2 - Valores de $p$ da análise de variância (ANOVA) referente a média da massa seca da parte aérea (MSPA - g planta $^{-1}$ ), massa seca das raízes (MSR g planta $^{-1}$ ), massa seca total (MST g planta ${ }^{-1}$ ), razão entre MSPA/MSR, índice de clorofila (IC) teor de fósforo da parte aérea (PPA $\left(\mathrm{mg} \mathrm{g}^{-1}\right)$ do tomateiro inoculado com o FMA Rhizophagus clarus sob a adição ou não de substâncias húmicas (SHs).

\begin{tabular}{|c|c|c|c|c|c|c|}
\hline Tratamentos & MSPA & MSR & MST & MSPA/MSR & $\mathrm{IC}$ & PPA \\
\hline \multicolumn{7}{|l|}{ FMA } \\
\hline Sem FMA & $6,91 \pm 0,31$ & $1,32 \pm 0,08$ & $8,23 \pm 0,34 b$ & $5,40 \pm 0,45$ & $58,37 \pm 1,84$ & $5,85 \pm 0,13 b$ \\
\hline Com FMA & $7,63 \pm 0,23$ & $1,52 \pm 0,11$ & $9,16 \pm 0,27 \mathrm{a}$ & $5,26 \pm 0,41$ & $59,98 \pm 1,26$ & $6,32 \pm 0,04 \mathrm{a}$ \\
\hline Valor de $P$ & 0,088 & 0,202 & 0,048 & 0,826 & 0,480 & 0,004 \\
\hline \multicolumn{7}{|l|}{ SHs } \\
\hline Sem SHs & $6,62 \pm 0,22 \mathrm{~b}$ & $1,34 \pm 0,11$ & $7,97 \pm 0,22 b$ & $5,30 \pm 0,54$ & $55,53 \pm 1,04 b$ & $5,89 \pm 0,14 \mathrm{~b}$ \\
\hline Com SHs & $7,93 \pm 0,19 \mathrm{a}$ & $1,51 \pm 0,08$ & $9,44 \pm 0,25 \mathrm{a}$ & $5,36 \pm 0,27$ & $62,82 \pm 1,05 a$ & $6,27 \pm 0,06 \mathrm{a}$ \\
\hline Valor de $P$ & $<0,001$ & 0,257 & $<0,001$ & 0,924 & $<0,001$ & 0,029 \\
\hline \multicolumn{7}{|l|}{ FMA $\times$ SHs } \\
\hline Sem FMA e sem SHs & $6,07 \pm 0,22 \mathrm{~b}$ & $1,28 \pm 0,12$ & $7,36 \pm 0,15 c$ & $5,04 \pm 0,78$ & $53,32 \pm 0,92 \mathrm{c}$ & $5,51 \pm 0,14 b$ \\
\hline Com FMA e sem SHs & $7,17 \pm 0,17 \mathrm{~b}$ & $1,41 \pm 0,20$ & $8,58 \pm 0,14 \mathrm{~b}$ & $5,57 \pm 0,82$ & $57,73 \pm 1,28 b$ & $6,28 \pm 0,05 a$ \\
\hline Sem FMA e com SHs & $7,76 \pm 0,21 \mathrm{ab}$ & $1,39 \pm 0,13$ & $9,15 \pm 0,32 \mathrm{ab}$ & $5,76 \pm 0,29$ & $63,41 \pm 1,32 \mathrm{a}$ & $6,19 \pm 0,09 \mathrm{a}$ \\
\hline Com FMA e com SHs & $8,09 \pm 0,34 \mathrm{a}$ & $1,63 \pm 0,06$ & $9,73 \pm 0,39 a$ & $4,96 \pm 0,15$ & $62,23 \pm 1,74 a$ & $6,36 \pm 0,06 a$ \\
\hline Valor de $P$ & $<0,001$ & 0,384 & $<0,001$ & 0,754 & $<0,001$ & $<0,001$ \\
\hline
\end{tabular}

Média \pm erro padrão. Médias seguidas da mesma letra na coluna, não diferem estatisticamente entre si pelo teste de Duncan $(\mathrm{p} \leq 0,05)$. 
A colonização radicular da planta adição de SHs foi de 10,90 e com adição de SH foi de 18,27 (Tabela 1). Porém, foi observada uma pequena incidência e esporos de FMA e colonização radicular (Tabela 1), isto pode ter ocorrido devido às mudas de tomateiro ter sido adquirida de um viveiro local, não qual não as mudas não estava sendo crescidas e substrato estéril. Como a colonização radicular nas plantas sem inoculação micorrízica foi insignificante, está pequena incidência não deve ter afetado os resultados encontrados.

A baixa colonização radicular por FMA no presente estudo pode ter sido devido a coleta do experimento com 48 dias após o transplanto das mudas e, além disso, a inoculação de 100 esporos de FMA por vaso, pode-se ter demonstrado insuficiente no presente estudo. No estudo de Demir et al. (2015), avaliaram a colonização radicular do tomateiro inoculado no FMA e com adição de ácido húmico e observaram que a colonização radicular variou de 21 a 44\%. Porém, no estudo de Douds Jr. et al. (2016) conduzido a campo por sete anos com plantas de tomate inoculadas com FMAs, observaram que colonização radicular do tomateiro inoculado vaiou de 1 a $10 \%$, mas, assim com baixa colonização, os autores concluíam que houve aumento significativo no crescimento e na produção do tomateiro, mesmo em condições que apresentam elevada presença e P. Isto indica que o tomateiro não apresenta uma elevada colonização radicular, como foi observada no presente estudo. Os FMAs podem aperfeiçoar esta produção, uma vez que a simbiose entre o fungo e as plantas pode promover o aumento da absorção de nutrientes. O FMA vem sendo utilizado em várias culturas. Com isso, pode ser uma alternativa, para aumentar a produção, sem a aplicação de insumos agrícolas (SMITH; READ, 2008).

A resposta positiva no aumento da densidade de esporos e a colonização radicular por FMA com a adição de SHs no presente estudo, pode levar a um aumento no crescimento e absorção de $\mathrm{P}$ pelo tomateiro, devido ao papel dos FMAs em estimular o crescimento das plantas e absorção de nutrientes.

A massa seca da parte aérea (MSPA) aumentou significativamente com a inoculação do FMA e com a adição de SHs (Tabela 2). A adição de SHs estimulou a produção de MSPA, pois os dois tratamentos com a SHs obtiveram melhores resultados. No estudo realizado por Rady e Rehmman, (2016) também observaram aumento significativo no crescimento do tomateiro quando adicionado ácido húmico no substrato de produção.

Os resultados encontrados para a massa seca da raiz (MSR) não foram significativos para os tratamentos somente com FMA e o tratamento com inoculada com FMA sem a SHs, ou a interação entre FMA e SHs (Tabela 2). Candido et al. (2015), estudando a planta de tomate em condições de campo inoculado com FMA, encontraram aumento significativo no crescimento e desenvolvimento do tomateiro, além da produção de frutos maiores e com mais qualidade, quando comparado com o controle não inoculado.

A produção de massa seca total (MST) aumentou significativamente quando inoculado o FMA e adicionado as SHs (Tabela 2). No tratamento sem inoculação de FMA e sem adição de $\mathrm{SH}$ o valor foi de 7,36 g planta $^{-1}$, o maior resultado foi de 9,73 quando foi inoculado o FMA e a SH (Tabela 2). Resultados similares foram obtidos para a cultura da bananeira (Musa paradisiaca) clone horton (BARRERA-VIOLETH et al., 2012) e milho (ZHU et al., 2012), nos quais esses autores também observaram um aumento significativo da MST com a inoculação micorrízica.

O índice de clorofila (IC) foi elevado significativamente com a adição de SHs (Tabela 2). A inoculação do FMA e a presença de SHs não diferiram significantemente do tratamento somente com as $\mathrm{SHs}$, mas sem a adição de SHs a inoculação com FMA aumentou o IC comparado com o controle (Tabela 2). Isso indica que as SHs e a inoculação com FMA aumentou a atividade fotossintética da cultura do tomateiro, levando a uma maior produção de fitomassa. Kaschuk et al. (2010), estudando plantas da família Fabaceae inoculadas com FMAs concluíram usando meta-análises que as plantas tiveram a atividade fotossintética aumentada devido à associação micorrízica.

O teor de fósforo na parte aérea (PPA) da planta aumentou significantemente com a inoculação de FMA e com adição de SHs, comparado com o tratamento controle sem inoculação de FMA e sem adição de $\mathrm{SHs}$ (Tabela 2). As SHs têm a capacidade de regular e estimular o crescimento e desenvolvimento da planta, assim interferindo nos processos metabólicos e fisiológicos e na absorção e melhor uso de nutrientes pela planta (CHEN; AVAID, 1990; NARDI et al., 2002; ZANDONADI et al., 2014).

Alguns estudos conduzidos a campo e em vasos, também demostraram um efeito significativo no crescimento e absorção de nutrientes do tomateiro quando a planta estava inoculada com FMAs (LATEF; CHAOXING, 2011; ORTAS et al., 2013; WATTSWILLIAMS et al., 2014, HAR'T et al., 2015),

A absorção de $\mathrm{P}$ do solo é realizada pelas raízes, mas pode ser feita também pelo micélio externo dos FMA, como mostrado em estudos com Glomus etunicatum em raízes de Lolium perene (L.) (SMITH; READ, 2008). 
Um dos pontos positivos no metabolismo da planta com a aplicação de ácidos húmicos $(\mathrm{AH})$, é o aumento de absorção de nutrientes com N, P, Ca, K, $\mathrm{Mg}, \mathrm{Fe}, \mathrm{Zn}$ e $\mathrm{Cu}$ (DAVIS et al., 1994; ADANI et al., 1998, DEMIR et al., 2015).

Baum et al. (2015), em recente revisão, concluíram que inoculação com FMAs aumenta a produção de olerícolas como a tomate, pois tem efeito no crescimento da planta, aumenta a tolerância a estresses abióticos (hidrico e salino), aumenta a absorção de nutrientes diminui estresse bióticos causados por fitopatógenos como, nematoides (SHARMA; SHARMA, 2017). Uma tecnologia com um futuro promissor é a combinação da inoculação micorrízica com a aplicação de biofertilizantes (microorganismos promotores de crescimento e $\mathrm{SHs}$ ) podendo levar a um aumento considerável na produção vegetal (CALVO-POLANCO et al., 2016).

O presente estudo de mostra o efeito positivo na inoculação do tomateiro com FMA e da adição de SHs. A interação da inoculação com FMA e adição de $\mathrm{SHs}$ apresentou um efeito sinergético no desenvolvimento desta planta. Nos estudos de Conversa et al. (2013), Hart et al. (2015) e Bona et al. (2017), afirmaram que a aplicação de algumas espécies de FMAs como biofertilizante para o tomateiro é considerada uma prática inovadora e eco-sustentável, aumentando a rentabilidade dos produtores e reduzindo a necessidade de aplicação de fertilizantes fosfatados e aumenta a qualidade industrial e nutricional do tomate. Isso foi observado no presente estudo com o aumento da MSPA, MST, IC e PPA nas plantas inoculadas com o FMA $R$. clarus e ou com a adição de SHs.

\section{CONCLUSÃO}

A inoculação com o FMA Rhizophagus clarus e adição de substâncias húmicas, aumentaram o crescimento da planta de tomateiro e o conteúdo de fósforo, podendo levar a um aumento produção e redução de custos pelos produtores de tomate.

\section{AGRADECIMENTOS}

Os autores agradecem a Universidade Paranaense - UNIPAR pelo apoio à pesquisa. Odair Alberton agradece a bolsa produtividade de pesquisa concebida pelo CNPq.

\section{REFERÊNCIAS}

ADINI, F.; GENEVINI, P.; ZACHHEO, P. The effect of commercial humic acid on tomato plant gowth and mineral nutrition. Journal of Plant Nutrition. v. 21, p. 561-575, 1998.

BARRERA-VIOLETH, J. L.; OVIEDO-ZUMAQUE, L. E,; BARRAZA-ÁLVAREZ F. V. Evaluación de micorrizas nativas en plantas de plátano Hartón (Musa AAB Simmonds) en fase de viveiro. Acta Agronómica. v. 61, p. 315-324, 2012.

BONA, E.; CANTAMESSA, S.; MASSA, N.; MANASSERO, P.; MARSANO, F.; COPETTA, A.; LINGUA, G.; D'AGOSTINO, G.; GAMALERO, E.; BERTA, G. Arbuscular mycorrhizal fungi and plant growth-promoting pseudomonads improve yield, quality and nutritional value of tomato: a field study. Mycorrbiza. v. 27, p. 1-11, 2017.

BRASIL - IBGE - Instituto Brasileiro de Geografia e Estatística. Levantamento Sistemático da Produção Agrícola (LSPA), Abril de 2016.

CALVO-POLANCO, M.; SÁNCHES-ROMERA, B.; AROCA, R.; ASINS, M. J.; DECLERCK, S.; DODD, I. C.; MARTÍNEZ-ANDÚJAR, C.; ALBACETE, A.; RUIZ-LOZANO, J. M. Exploring the use of recombinant inbred lines in combination with beneficial microbial inoculants (AM fungus and PGPR) to improve drought stress tolerance in tomato. Environmental and Experimental Botany. v.131, p. 47-57, 2016.

CANDIDO, V.; CAMPANELLI, G.; D'ADDABBO, T.; CASTRONUOVO, D.; PERNIOLA, M.; CAMELE, I. Growth and yield promoting effect of artificial mycorrhization on field tomato at different irrigation regimes. Scientia Horticulturae. v.187, p. 35-43. 2015.

CHEN, Y.; AVIAD, T. Effects of humic substances on plant growth. In: McCARTHY, P., editor. Humic substances in soil and crop sciences: Selected readings, Chicago: CAB, p.161-87, 1990.

CHITARRA, W.; PAGLIARANI, C.; MASERTI, B.; LUMINI, E.; SICILIANO, I.; CASCONE, P.; SCHUBERT, A.; GAMBINO, G.; BALESTRINI, R.; GUERRIERI, E. Insights on the impact of arbuscular mycorrhizal symbiosis on tomato tolerance to water stress. Plant Physiology. v.171, p. 1009-1023, 2016. 
CONVERSA, G.; LAZZIZERA, C.; BONASIA, A.; ELIA, A. Yield and phosphorus uptake of a processing tomato crop grown at different phosphorus levels in a calcareous soil as affected by mycorrhizal inoculation under field conditions. Biology and Fertility of Soils. v. 49, p. 691-703, 2013.

DAVIS, P. P.; NELSON, P. V.; SANDERS, D. C. A humic acid improves growth of tomato seedling in solution culture. Journal Plant Nutrition. v. 17, p. 173184, 1994.

DEMIR, S.; SENSOY, S.; OCAK, E.; TUFENKCI, E.; DURAK, E. D.; ERDINC, C.; UNSAL, H. Effects of arbuscular mycorrhizal fungus, humic acid, and whey on wilt disease caused by Verticillium dabliae Kleb. in three solanaceous crops. Turkish Journal of Agriculture and Forestry. v. 39, p. $300-309,2015$.

DOUDS JR., D.D.; LEE, J.; MCKEEVER, L.; ZIEGLER-ULSH, C.; GANSER, S. Utilization of inoculum of AM fungi produced on-farm increases theyield of Solanum lycopersicum: A summary of 7 years of field trials ona conventional vegetable farm with high soil phosphorus. Scientia Horticulturae. v. 207, p. 89-96, 2016.

FALKER AUTOMAÇÃO AGRÍCOLA LTDA. Manual do medidor eletrônico de clorofila ClorofiLOG CFL 1030, Porto Alegre, v. 4, 2008.

GERDEMANN, J. W.; NICOLSON, T. H. Spores of mycorrhizal endogone species extracted from soil by wet sieving and decanting. Transactions of the British Mycological Society. v. 46, p. 235-246, 1963.

GIOVANNETTI, M.; MOSSE, B. An evaluation of techniques for measuring VA mycorrhizal infection in roots. New Phytologist, v. 84, p. 489-500, 1980.

HART, M.; EHRET, D. L.; KRUMBEIN, A.; LEUNG, C.; MURCH, S.; TURI, C.; FRANKEN, P. Inoculation with arbuscular mycorrhizal fungi improves the nutritional value of tomatoes. Mycorrbiza. v. 25, p. 359-376, 2015.

HOAGLAND, D. R.; ARNON, D. I. The water culture method for growing plants without soil. California Agricultural Experiment Station, vol. 347, 32p, 1950.
KASCHUK, G.; LEFFELAAR, P. A.; GILLER, K. E.; ALBERTON, O.; HUNGRIA, M.; KUYPER, T. W. Responses of legumes to rhizobia and arbuscular mycorrhizal fungi: A meta-analysis of potential photosynthate limitation of symbioses. Soil Biology and Biochemistry. v. 42, p. 125-127, 2010.

LATEF, A.A.A.H.; CHAOXING, H. Effect of arbuscular mycorrhizal fungi on growth, mineral nutrition, antioxidant enzymes activity and fruit yield of tomato grown under salinity stress. Scientia Horticulturae. v. 127, p. 228-233, 2011.

LERMEN, C.; MOHR, F.B.M.; ALBERTON, O. Growth of Cymbopogon citratus inoculated with mycorrhizal fungi under different levels of lead. Scientia Horticulturae. v. 186, p. 239-246, 2015.

LIMA, A. A.; ALVARENGA M. A. R.; RODRIGUES L.; CARVALHO J. G. Concentração foliar de nutrientes e produtividade de tomateiro cultivado sob diferentes substratos e doses de ácidos húmicos. Horticultura Brasileira. v. 29, p. 63-69, 2011

NARDI, S.; PIZZEGHELLO, D.; MUSCOLO, A.; VIANELLO, A. Physiological effects of humic substances onhigher plants. Soil Biology and Biochemistry. v. 34, p. 1527-36, 2002.

ORTAS, I.; SARI, N.; AKPINAR, C.; YETISIR, H. Selection of arbuscular mycorrhizal fungi species for tomato seedling growth, mycorrhizal dependency and nutrient uptake. European Journal of Horticultural Science. v.78, p.209-218, 2013.

PEINADO-GUEVARA, L.I.; LÓPEZ-MEYER, M.; LÓPEZ-VALENZUELA, J.A.; MALDONADOMENDOZA, I.E.; GALINDO-FLORES, H.; CAMPISTA-LEÓN, S.; MEDINA-GODOY, S. Comparative proteomic analysis of leaf tissue from tomato plants colonized with Rhizophagus irregularis. Symbiosis, 2017. doi:10.1007/s13199-016-0470-.

PHILLIPS, J. M.; HAYMAN, D. S. Improved procedures for clearing roots and staining parasitic and vesicular-arbuscularr mycorrhizal fungi for rapid assessment of infection. Transactions of the British Mycological Society. v.55, p.157-160, 1970. 
PINHEIRO, G. L.; SILVA, C. A.; FURTINI NETO, A. E. Growth and nutrition of eucalyptus clone as affected by the application of c-humic acid doses. Revista Brasileira de Ciência do Solo. v. 34, n. 4, p. 12171229, 2010.

RADY, M. M.; REHMAN, H. Supplementing organic biostimulants into growing media enhances growth and nutrient uptake of tomato transplants. Scientia Horticulturae, v. 203, p. 192-198, 2016.

SHAMA, I. P.; SHARMA, A. K. Physiological and biochemical changes in tomato cultivar PT-3 with dual inoculation of mycorrhiza and PGPR against root-knot nematode. Symbiosis. v. 71, p. 175-183, 2017.

SILVA, C. F. Manual de análises químicas de Solos, plantas e fertilizantes. 2 ed. Brasília DF: Embrapa, 2009, p. 243-627.

under drought stress. Plant Soil Environment. v. 58, p. 186-191, 2012.
SMITH, S. E., READ, D. J. Mycorrbizal symbiosis, Academic Press. $3^{a}$ ed. 2008. 787 p.

WATTS-WILLIAMS, S. J.; TURNEY, T. W.; PATTI, A. F.; CAVAGNARO, T. R. Uptake of zinc and phosphorus by plants is affected by zinc fertiliser material and arbuscular mycorrhizas. Plant Soil. v. 376, p. $165-175,2014$

ZANDONADI, D. B.; SANTOS, M. P.; MEDICI, L. O.; SILVA, J. Ação da matéria orgânica e suas frações sobre a fisiologia de hortaliças. Horticultura Brasileira. v. 32, p.14-20, 2014.

ZHU, X. C.; SONG, F. B.; LIU, S. Q.; LIU, T. D.; ZHOU, X. Arbuscular mycorrhizal e improves photosynthesis and water status of Zea mays $\mathrm{L}$. 